\title{
I $\quad$ Birth order and sibship composition as predictors of overweight or obesity among low-income 4- to 8-year-old children
}

\author{
R. H. Mosli ${ }^{1,2}$, A. L. Miller ${ }^{3,4}$, K. E. Peterson ${ }^{1,4,5}$, N. Kaciroti ${ }^{4}$, K. Rosenblum ${ }^{4,6}$, A. Baylin ${ }^{7}$ \\ and J. C. Lumeng ${ }^{1,4,8}$
}

\begin{abstract}
${ }^{1}$ Human Nutrition Program, Department of Environmental Health Sciences, School of Public Health, University of Michigan, Ann Arbor, MI, USA; ${ }^{2}$ Clinical Nutrition Department, Faculty of Applied Medical Sciences, King Abdulaziz University, Jedddah, KSA; ${ }^{3}$ Department of Health Behavior and Health Education, School of Public Health, University of Michigan, Ann Arbor, MI, USA; ${ }^{4}$ Center for Human Growth and Development, University of Michigan, Ann Arbor, MI, USA; ${ }^{5}$ Department of Nutrition, Harvard School of Public Health, Boston, MA, USA; ${ }^{6}$ Department of Psychiatry, University of Michigan, Ann Arbor, MI, USA; ' Department of Epidemiology, School of Public Health, University of Michigan, Ann Arbor, MI, USA; ${ }^{8}$ Department of Pediatrics and Communicable Diseases, University of Michigan, Ann Arbor, MI, USA
\end{abstract}

Address for correspondence: Ms RH Mosli, Human Nutrition Program, Department of Environmental Health Sciences, School of Public Health, 6655 SPH I, Ann Arbor, MI 48109-2029, USA. E-mail: rmosli@umich.edu

Received 26 September 2014; accepted 27 January 2015

\section{Summary}

Objective: This study aimed to examine the association of birth order and number and sex of siblings with overweight or obesity among 4- to 8-year-olds.

Methods: This is a cross-sectional study involving 273 low-income mother-child dyads. Questionnaires and anthropometry were completed. Multiple logistic regression was used to examine the association of birth order, having younger siblings, having older siblings, having at least one brother and having at least one sister with odds of overweight or obesity. Analyses were repeated to additionally include non-biological siblings. Models were adjusted for potential confounders and intermediate variables.

Results: Prevalence of child overweight or obesity was 42.5\%. Adjusting for covariates, only children and youngest siblings had higher odds of overweight or obesity compared with oldest siblings (odds ratio [OR]: 4.18, 95\% confidence interval [Cl]: 1.67, 10.46 and OR: 3.21, 95\% Cl: 1.41, 7.33, respectively). Having one or more younger siblings and having at least one brother were associated with lower odds (OR: 0.38, 95\% Cl: 0.21, 0.69 and OR: 0.47, 95\% Cl: 0.28, 0.81, respectively). Including non-biological siblings did not meaningfully change the associations.

Conclusion: Birth order and sibship composition are associated with overweight or obesity among 4- to 8-year-olds. Future studies identifying the underlying behavioural mechanism can help inform family-based intervention programmes.

Keywords: Birth order, odds of overweight or obesity, sibship composition.

\section{Introduction}

In 2012, a third of United States (US) children and adolescents were estimated to be overweight or obese (OWOB) (1). Identifying children who have higher obesity risk can help researchers and practitioners target interventions more effectively. In addition, understanding the underlying mechanisms for increased risk can help enhance these interventions and optimize their outcomes. Although specific demographic characteristics, such as socioeconomic status (SES), have received substantial attention in the prior literature, associations of birth order and sibship composition (i.e. number and sex of siblings) with childhood obesity are not well established. As divorce rates have increased and fertility rates have decreased, families have become smaller and the number of children growing up without other children in the household has increased (2). These shifts in family structure and size during the past three decades now make it especially important to understand the associations of birth order and sibship composition with childhood obesity. Because more US children are now growing up with fewer brothers and sisters or without siblings, examining these associations can help target and inform obesity preventive interventions for a relatively large proportion of the population.

A number of reports have described a conflicting set of findings regarding the association of birth order and number of siblings with weight status (3-13). Some studies have found that being an only child $(3-6,12,13)$ or a youngest sibling $(4,13)$ was associated with a higher risk of obesity. However, other studies have reported that only children and youngest siblings were less likely to be obese (8-10), and others have reported no association $(7,11)$. Some reports have described an inverse association of number of siblings (6), or number of younger siblings (4) with risk of obesity. However, others found no association (11). These 
discrepant findings may be due to methodological distinctions, including differences in the definition of birth order categories (i.e. combining only children and oldest siblings in the same comparison group vs. allocating them in separate categories) and age of study participants.

There are several additional gaps in the existing literature. First, potential confounders such as maternal education, which may be associated with both parity (14) and child weight status (6), were often not considered. In addition, most studies did not take into account potential intermediate variables (e.g. maternal relationship status), which can help us determine whether the associations are entirely explained by these variables, or whether future studies are needed to explore the potential underlying mechanism of association. Second, to our knowledge, no prior study in the US has tested the hypothesis that being a youngest sibling is an independent predictor of weight status $(4,13)$ Third, siblings' sex characteristics have been associated with perceived parenting behaviour (15) and outcomes of a family-based obesity intervention (16), but prior studies have not examined the association between sex of siblings and child weight status $(3-6,13)$. Finally, most studies $(3,4,6,13)$ did not specifically focus on low-income groups that are at significantly higher risk of obesity (1).

The goals of this study were to examine the associations of only child status, youngest sibling status and sibship composition (i.e. number and sex of siblings) with odds of overweight or obesity in low-income US families while taking into account potential confounders and intermediate variables.

\section{Methods}

\section{Sample}

The study sample includes 301 child-mother dyads recruited through Head Start programmes in South Central Michigan. Head Start is a federally funded preschool programme for low-income, high-risk families in the US. Most participants were drawn from a longitudinal cohort initiated in 2009 to investigate associations between stress and eating among low-income children. The cohort was augmented with 18 additional caregiver-child dyads who were recruited in May 2013 by flyers distributed to Head Start locations describing a study on feeding behaviour. Children described in this study were therefore between the ages of 4 and 8 years at the time of data collection. Inclusion criteria were caregiver is fluent in English and does not have a college degree; and child is not in foster care, has no serious medical problems or history of food allergies and was born at $\geq 35$ weeks gestation without significant perinatal or neonatal complications. Because this study takes into account maternal weight, which might influence the child's weight status through hereditary factors and early life exposures, we limited the sample to participants living with their biological mothers $(n=281)$. Five children with missing data and three children who had a same age sibling were also excluded, leaving a final sample of 273. The sample included in this analysis $(n=273)$ did not differ from the sample not included $(n=28)$ with regard to child sex, child race/ethnicity and maternal education. Mothers provided written informed consent for themselves and for their children. The University of Michigan Institutional Review Board approved this study.

\section{Measures}

During two study visits, mothers completed questionnaires alone and anthropometric measurements were taken from mothers and children. Because of the high prevalence of low literacy in this sample, research assistants read questions and response options aloud from a computer, and then entered mothers' answers.

\section{Study outcome: child overweight or obesity status}

Trained staff members measured weight and height following standardized procedures. Shoes and heavy clothing were removed. Each individual was weighed twice and if the two readings were inconsistent by more than $0.1 \mathrm{~kg}$, the individual was weighed two more times. Similarly, height was measured twice; if the measurements differed by more than $0.5 \mathrm{~cm}$, two more measurements were taken. All available measures were averaged for analysis. Body mass index (BMI) was calculated by dividing weight $(\mathrm{kg})$ by height ${ }^{2}$ $\left(\mathrm{m}^{2}\right)$, and percentiles were derived based on the revised Centers for Disease Control growth charts. A body mass index $(\mathrm{BMI}) \geq 85$ th percentile was categorized as OWOB.

\section{Primary predictors: birth order and sibship composition}

Mothers provided information regarding individuals living in the household, including each individual's age, sex and relationship to the index child. The five primary predictors created from this information were: (i) a four-category variable for birth order, categorized as only child, youngest sibling, middle sibling and oldest sibling. Disjoint indicator variables were used for each birth order category, with 'oldest sibling' as the reference category; (ii) a dichotomous variable for having one or more younger siblings; (iii) a dichotomous variable for having one or more older siblings; (iv) a dichotomous variable for having at least one brother; (v) a dichotomous variable for having at least one sister. We defined these variables in two alternative ways. First, we included only biologically related siblings in our definitions. Second, to examine differences by biological relatedness of siblings, we created these variables again additionally including non-biological siblings living in the same household as the index child $(n=51)$. In both analyses we retained all $(n=273)$ index children in the study sample.

\section{Covariates}

We identified additional characteristics for which to adjust in our statistical models a priori from theliterature. Mothers reported information regarding socio-demographic characteristics, including child's sex, child's age, child's race/ 
ethnicity and mother's birth date, years of education and relationship status. The 18-item US Department of Agriculture Food Security Scale (17) was used to create a twolevel variable to categorize households as food secure or food insecure. Mothers completed the 20-item Center for Epidemiologic Studies-Depression scale and a score $\geq 16$ (18) defined clinically significant depression symptoms. Mothers' weight and height were measured using standardized procedures and BMl was calculated. Mothers reported the child's birth weight, which was converted to $z$-scores based on National Datasets (19). Birth weight $z$-scores were missing and were imputed for 26 subjects using Proc MI in SAS (SAS Institute Inc. Cary, NC, USA).

\section{Statistical analysis}

Statistical analyses were conducted using IBM SPSS Statistics 21.0 (Armonk, NY, USA). We ran descriptive statistics to assess characteristics of the full sample, and bivariate analyses by OWOB status using $t$-tests for continuous variables and chi-square tests for categorical variables.

We ran separate logistic regression models for each of the five primary predictors. We first ran the regression models without adjusting for any covariates. Then, we reran the models controlling only for potential confounders, including child's sex, child's age, child's race/ethnicity, maternal age and maternal education. Each of these variables might be associated with fertility choices $(14,15,20,21)$, which may affect the number of brothers and sisters a child has as well as his or her birth order (e.g. being an only child vs. not). Child's sex, child's age, child's race/ethnicity, maternal age and maternal education are also associated with child overweight $(1,6,22)$. Next, in order to examine the direct effect of each of the primary predictors on weight status, we reran the models to additionally include covariates that may be located in the causal pathway. Birth order (being an only child vs. not) and number of brothers and sisters have been associated with maternal relationship status (15), amount of resources available (23) (measured here as household food insecurity), maternal depression symptoms (24), maternal BMI $(22,25)$ and child birth weight $(19,22)$. Each of these variables has in turn been associated with child overweight $(6,22,26,27)$. We therefore included them as potential intermediate variables in the five fully adjusted models. The Wald test statistic was used and significance level was set at 0.05. Furthermore, we included in each of the fully adjusted models an interaction term of index child's sex with the primary predictor and tested if the interaction term was statistically significant $(P$-value $<0.10)$. Finally, we reran each of these five fully adjusted models replacing the primary predictor variables with their versions that also included non-biological siblings.

\section{Results}

About half of the children were male (50.9\%). Mean child age was 5.4 years ( \pm standard deviation [SD] 0.8) and approximately half of the children (53.8\%) were non-
Hispanic white. The prevalence of OWOB in the sample was $42.5 \%$. Mean maternal BMl was higher among OWOB children (36.3 \pm SD 10.0) compared with non-OWOB children (30.6 \pm SD 8.3). Children who were OWOB also had higher birth weights (Table 1). Thirty-nine children (14.3\%) were only children, 100 (36.6\%) were youngest siblings, 66 (24.2\%) were middle siblings and 68 (24.9\%) were oldest siblings. In unadjusted bivariate analyses, birth order and having one or more younger siblings were associated with prevalence of OWOB status. Having at least one brother was associated with higher prevalence of non-OWOB status (Table 1).

\section{Birth order and child overweight or obesity}

As shown in Table 2, adjusting for all covariates, only children had higher odds of being OWOB compared with oldest siblings (odds ratio [OR]: 4.18, 95\% confidence interval [Cl]: 1.67, 10.46). Youngest siblings had higher odds of being OWOB compared with oldest siblings (OR: 3.21, 95\% Cl: 1.41, 7.33). The OR for middle siblings to oldest siblings was $1.71(95 \% \mathrm{Cl}$ : $0.76,3.86$, $P$-value $=0.19)$. The OR for youngest siblings to only children was 0.77 (95\% Cl: 0.33, 1.80, $P$-value $=0.54)$. The odds of being OWOB for middle siblings compared with only children approached statistical significance (OR: 0.41, 95\% Cl: 0.17, 1.00, $P$-value $=0.05$ ) as did the odds for middle siblings compared with youngest siblings (OR: 0.53, 95\% Cl: 0.25, 1.11, $P$-value $=0.09$ ).

\section{Sibship composition and child overweight or obesity}

As shown in Table 2, having one or more younger siblings was associated with lower odds of overweight or obesity (OR: 0.38, 95\% Cl: 0.21, 0.69). However, having one or more older siblings was not significantly associated with odds of being OWOB (OR: 1.28, 95\% Cl: 0.71, 2.31, $P$-value $=0.41)$. Having at least one brother was associated with lower odds of being OWOB (OR: 0.47, 95\% Cl: $0.28,0.81)$. Having at least one sister had no significant association with odds of being OWOB (OR: 1.10, 95\% Cl: $0.64,1.89, P$-value $=0.72$ )

\section{Interaction with index child's sex}

There was no significant interaction between index child's sex and any of the five primary predictors (all $P$-values $>0.50$ ).

\section{Inclusion of non-biological siblings}

When we reran the analyses replacing each of the primary predictor variables with their versions that also included non-biological siblings, the results were essentially unchanged (Table 3).

To examine whether the associations differ between children who are overweight as compared with those who are 
Table 1 Characteristics of total sample and differences by weight status

\begin{tabular}{|c|c|c|c|c|}
\hline Variables & $\begin{array}{l}\text { Total } \\
n=273\end{array}$ & $\begin{array}{l}\text { BMI }<85 \text { th } \\
\text { percentile } \\
n=157\end{array}$ & $\begin{array}{l}\text { BMI } \geq 85 \text { th } \\
\text { percentile } \\
n=116\end{array}$ & $P$-value \\
\hline Birth order, $n(\%)$ & & & & 0.02 \\
\hline Only child & 39 (14.3) & $16(10.2)$ & 23 (19.8) & \\
\hline Youngest sibling & $100(36.6)$ & $53(33.8)$ & $47(40.5)$ & \\
\hline Middle sibling & $66(24.2)$ & $41(26.1)$ & $25(21.6)$ & \\
\hline Oldest sibling & $68(24.9)$ & $47(29.9)$ & $21(18.1)$ & \\
\hline Index child has $\geq 1$ younger sibling, $n$ (\%) & & & & 0.01 \\
\hline Yes & $134(49.1)$ & $88(56.1)$ & $46(39.7)$ & \\
\hline No & $139(50.9)$ & 69 (43.9) & $70(60.3)$ & \\
\hline Index child has $\geq 1$ older sibling, $n(\%)$ & & & & 0.80 \\
\hline Yes & $166(60.8)$ & 94 (59.9) & $72(62.1)$ & \\
\hline No & $107(39.2)$ & $63(40.1)$ & $44(37.9)$ & \\
\hline Index child has $\geq 1$ brother, $n(\%)$ & & & & 0.01 \\
\hline Yes & $112(41.0)$ & $104(66.2)$ & 57 (49.1) & \\
\hline No & $161(59.0)$ & $53(33.8)$ & $59(50.9)$ & \\
\hline Index child has $\geq 1$ sister, $n(\%)$ & & & & 0.68 \\
\hline Yes & $142(52.0)$ & $80(51.0)$ & $62(53.4)$ & \\
\hline No & $131(48.0)$ & $77(49.0)$ & $54(46.6)$ & \\
\hline Child sex, $n(\%)$ & & & & 0.05 \\
\hline Male & $139(50.9)$ & $88(56.1)$ & $51(44.0)$ & \\
\hline Female & $134(49.1)$ & 69 (43.9) & $65(56.0)$ & \\
\hline Child race/ethnicity, $n$ (\%) & & & & 0.13 \\
\hline Non-Hispanic white & $147(53.8)$ & $91(58.0)$ & $56(48.3)$ & \\
\hline Hispanic or not white & $126(46.2)$ & $66(42.0)$ & $60(51.7)$ & \\
\hline Maternal age, M (SD) & $30.4(5.80)$ & $30.6(6.2)$ & $30.02(5.2)$ & 0.43 \\
\hline Maternal education, $n(\%)$ & & & & 0.28 \\
\hline$\leq$ High school education & $129(47.3)$ & $78(49.7)$ & $51(44.0)$ & \\
\hline >High school education & $144(52.7)$ & $79(50.3)$ & $65(56.0)$ & \\
\hline Maternal relationship status, $n$ (\%) & & & & 1.00 \\
\hline Single & $123(45.1)$ & $71(45.2)$ & $52(44.8)$ & \\
\hline Not single & $150(54.9)$ & $86(54.8)$ & $64(55.2)$ & \\
\hline Household food insecurity, $n$ (\%) & & & & 0.35 \\
\hline Food secure & $84(30.8)$ & $52(33.1)$ & $32(27.6)$ & \\
\hline Food insecure & $189(69.2)$ & $105(66.9)$ & $84(72.4)$ & \\
\hline Maternal depression symptoms, $n$ (\%) & & & & 1.00 \\
\hline CES-D $\geq 16$ & $85(31.1)$ & 49 (31.2) & $36(31.0)$ & \\
\hline CES-D $<16$ & $188(68.9)$ & $108(68.8)$ & 80 (69.0) & \\
\hline Maternal BMI, M (SD) & $33.0(9.45)$ & $30.6(8.28)$ & $36.3(9.96)$ & 0.00 \\
\hline Birth weight $z$-score, M (SD) & $-0.27(1.02)$ & $-0.43(0.91)$ & $-0.04(1.12)$ & 0.00 \\
\hline
\end{tabular}

Table showing means (M) and standard deviations (SD) or counts ( $n$ ) and percentages (\%). Significant differences between weight status groups tested by $t$-tests for continuous variables and chi-square tests for categorical variables. BMl, body mass index; CES-D, The Center for Epidemiologic StudiesDepression scale.

obese, we conducted a multinomial regression analysis with a three-category outcome variable (obese status, overweight status, non-OWOB status). Results suggested that the patterns of associations are the same across children who are overweight as compared with those who are obese.

\section{Discussion}

We found that being an only child or the youngest sibling as well as having no younger siblings or no brothers were each associated with higher odds of overweight or obesity. Results were not attenuated by inclusion of maternal, child 
Table 2 Associations between birth order and sibship composition with odds of overweight or obesity (BMl 285 th percentile) including only biological siblings

\begin{tabular}{|c|c|c|c|}
\hline & $\begin{array}{l}\text { Unadjusted odds ratios } \\
(95 \% \mathrm{Cl})(n=273)\end{array}$ & $\begin{array}{l}\text { Odds ratios } \\
(95 \% \mathrm{Cl})(n=273) \\
\text { Adjusted for } \\
\text { confounders only } \\
\end{array}$ & $\begin{array}{l}\text { Odds ratios }(95 \% \mathrm{Cl}) \\
(n=273) \\
\text { Adjusted for confounders } \\
\text { and intermediate variables }\end{array}$ \\
\hline \multicolumn{4}{|l|}{ Birth order category } \\
\hline Only child & $3.22(1.42,7.30)^{\star \star}$ & $3.68(1.55,8.68)^{\star \star}$ & $4.18(1.67,10.46)^{\star \star}$ \\
\hline Youngest sibling & $2.00(1.04,3.79)^{\star}$ & $2.71(1.27,5.77)^{\star \star}$ & $3.21(1.41,7.33)^{\star \star}$ \\
\hline Middle sibling & $1.39(0.67,2.79)$ & $1.68(0.79,3.61)$ & $1.71(0.76,3.86)$ \\
\hline Oldest sibling (reference) & 1 & 1 & 1 \\
\hline \multicolumn{4}{|c|}{ Index child has $\geq 1$ younger sibling } \\
\hline Yes & $0.51(0.31,0.83)^{\star \star}$ & $0.44(0.26,0.77)^{\star \star}$ & $0.38(0.21,0.69)^{\star \star}$ \\
\hline No (reference) & 1 & 1 & 1 \\
\hline \multicolumn{4}{|c|}{ Index child has $\geq 1$ older sibling } \\
\hline Yes & $1.09(0.67,1.79)$ & $1.24(0.72,2.16)$ & $1.28(0.71,2.31)$ \\
\hline No (reference) & 1 & 1 & 1 \\
\hline \multicolumn{4}{|l|}{ Index child has $\geq 1$ brother } \\
\hline Yes & $0.50(0.30,0.81)^{\star \star}$ & $0.49(0.30,0.81)^{\star \star}$ & $0.47(0.28,0.81)^{\star \star}$ \\
\hline No (reference) & 1 & 1 & 1 \\
\hline \multicolumn{4}{|l|}{ Index child has $\geq 1$ sister } \\
\hline Yes & $1.11(0.68,1.79)$ & $1.16(0.71,1.91)$ & $1.10(0.64,1.89)$ \\
\hline No (reference) & 1 & 1 & 1 \\
\hline
\end{tabular}

${ }^{*} P$-value $<0.05 .{ }^{* *} P$-value $<0.01$. ${ }^{\dagger}$ Models adjusted for potential confounders only: child sex, child age, child race/ethnicity, maternal age and maternal education. ${ }^{\prime}$ Models adjusted for potential confounders: child sex, child age child race/ethnicity, maternal age and maternal education and potential intermediate variables: maternal relationship status, household food insecurity, maternal depression symptoms, maternal BMl and birth weight $z$-score. $\mathrm{BMI}$, body mass index; $\mathrm{Cl}$, confidence interval.

and family characteristics that may be located in the causal pathway, and were essentially unchanged when nonbiological siblings were included in the analysis. These findings suggest that factors other than the ones considered here might explain the associations of birth order and sibship composition with child overweight or obesity.

Our findings are consistent with previous studies identifying a positive association between being an only child and overweight risk $(3-6,13)$. Although an earlier study found that not having siblings is not associated with obesity, this finding was based on data from Dutch adults in the 1970s (11), with a relatively low prevalence of obesity. To our knowledge, our study is the first in the US to report that youngest siblings may have higher odds of overweight or obesity. This finding is consistent with two previous studies in non-US populations $(4,13)$; the studies that did not find this association combined oldest siblings and only children into the same comparison group, which may be masking effects (8-10). In consensus with an earlier study (4), we observed that having younger siblings was associated with lower odds of overweight or obesity. In addition, although we could not identify any previous studies that examined the association between siblings' sex and children's weight status, we found that having at least one brother was also associated with lower odds of overweight or obesity.

Birth order (e.g. being an only child) and number of brothers and sisters might affect marital status (15), and children of single mothers are at higher risk of obesity (6). Having more siblings can be associated with fewer available resources (23) and food insecurity has been associated with lower risk of obesity among school-aged children (26). In addition, mothers with larger family sizes can be at higher risk for depression (24), which has been associated with childhood obesity (27). However, adjusting for maternal relationship status, household food insecurity and maternal depression symptoms did not change our results. Maternal weight (25) and child birth weight (19) tend to increase with parity, and higher maternal BMI and child birth weight are each associated with childhood obesity (22). However, when we included maternal BMl and child birth weight $z$-score in our models, the associations were not attenuated. These findings suggest that there may be other unrelated factors contributing to the underlying mechanism of association.

Behavioural characteristics and interaction patterns between family members may be the underlying mechanism explaining the association of birth order and sibship composition with weight status. For example, parenting styles in general have been shown to vary by children's birth order (23). This suggests that parenting styles specific to feeding, which can affect weight status (28), might also vary by birth order. Having more younger siblings may lead to more time spent in play, increasing caloric expenditure throughout the day, and having at least one brother can be associated with more positive interactions between family 
Table 3 Associations between birth order and sibship composition with odds of overweight or obesity (BMI $\geq 85$ th percentile) including both biological and non-biological siblings

\begin{tabular}{|c|c|c|c|}
\hline & $\begin{array}{l}\text { Unadjusted odds ratios } \\
(95 \% \mathrm{Cl})(n=273)\end{array}$ & $\begin{array}{l}\text { Odds ratios }(95 \% \mathrm{Cl}) \\
(n=273) \\
\text { Adjusted for } \\
\text { confounders only }{ }^{\dagger}\end{array}$ & $\begin{array}{l}\text { Odds ratios }(95 \% \mathrm{Cl}) \\
(n=273) \\
\text { Adjusted for } \\
\text { confounders and } \\
\text { intermediate variables }\end{array}$ \\
\hline \multicolumn{4}{|l|}{ Birth order category } \\
\hline Only child & $3.33(1.40,7.74)^{\star \star}$ & $3.88(1.56,9.63)^{\star \star}$ & $4.39(1.66,11.61)^{\star \star}$ \\
\hline Youngest sibling & $2.21(1.13,4.34)^{\star}$ & $3.07(1.41,6.67)^{\star \star}$ & $3.68(1.57,8.60)^{\star \star}$ \\
\hline Middle sibling & $1.63(0.79,3.34)$ & $2.01(0.97,4.48)$ & $2.26(0.99,5.10)$ \\
\hline Oldest sibling (reference) & 1 & 1 & 1 \\
\hline \multicolumn{4}{|c|}{ Index child has $\geq 1$ younger sibling } \\
\hline Yes & $0.53(0.33,0.87)^{\star}$ & $0.47(0.27,0.82)^{\star \star}$ & $0.42(0.23,0.76)^{\star \star}$ \\
\hline No (reference) & 1 & 1 & 1 \\
\hline \multicolumn{4}{|c|}{ Index child has $\geq 1$ older siblings } \\
\hline Yes & $1.24(0.75,2.05)$ & $1.44(0.82,2.51)$ & $1.52(0.84,2.76)$ \\
\hline No (reference) & 1 & 1 & 1 \\
\hline \multicolumn{4}{|l|}{ Index child has $\geq 1$ brother } \\
\hline Yes & $0.50(0.31,0.82)^{\star \star}$ & $0.50(0.30,0.83)^{\star \star}$ & $0.48(0.28,0.83)^{\star \star}$ \\
\hline No (reference) & 1 & 1 & 1 \\
\hline \multicolumn{4}{|l|}{ Index child has $\geq 1$ sister } \\
\hline Yes & $1.15(0.70,1.86)$ & $1.23(0.74,2.03)$ & $1.24(0.72,2.15)$ \\
\hline No (reference) & 1 & 1 & 1 \\
\hline
\end{tabular}

${ }^{\star} P$-value $<0.05$. ${ }^{*} P$-value $<0.01$. ${ }^{\dagger}$ Models adjusted for potential confounders only: child sex, child age, child race/ethnicity, maternal age and maternal education. ¥Models adjusted for potential confounders: child sex, child age, child race/ethnicity, maternal age and maternal education, and potential intermediate variables: maternal relationship status, household food insecurity, maternal depression symptoms, maternal BMI and birth weight $z$-score. $\mathrm{BMI}$, body mass index; $\mathrm{Cl}$, confidence interval.

members (15), and hence better family functioning during mealtimes. Future studies are needed to test these potential underlying behavioural mechanisms.

This study has several strengths. We explored the associations of birth order and sibship composition with weight status in a low-income, multiethnic US population. Additionally, we were uniquely positioned to further account for previously unexamined variables. Our study was the first to specifically examine the effect of siblings' sex and to distinguish between biological and non-biological siblings. This study has also some limitations. Our sample size is relatively small and therefore our power to detect some effects may have been limited. There might be residual confounding (e.g. by SES) or potential intermediate variables (e.g. physical activity) that we did not account for in our analysis. In addition, we did not measure or examine the influence of siblings' weight. Because our study included only Head Start families who chose to respond to a flyer, our findings may not be generalizable to individuals without these characteristics. Finally, our findings may only be relevant to 4- to 8-year-olds. It remains unknown if the effect of birth order and sibship composition persists later into the lifespan, but the pattern of findings in the existing literature suggests that the association weakens with age as most of the observed positive associations were seen in school-aged children $(3-6,12,13)$ as opposed to adolescence and adulthood (8-11).
Our findings can help practitioners and researchers better identify children at risk. Because we speculate that associations observed in this study are driven by family routines and functioning, further studies that aim to understand these underlying processes can help inform familybased interventions. Including multiple members of the family can improve obesity intervention outcomes (29). Our findings may motivate practitioners and researchers to explore parenting practices of only children and of youngest siblings as a component of family-based programmes. Future efforts may also include discussing with parents different interaction patterns between siblings and how they may relate to obesity risk. Parents can be influential in shaping relationships between siblings (30), and can therefore be educated to encourage sibling interactions that are associated with healthy eating and physical activity. Using birth order and sibship composition data could become a novel and successful approach to identify children at risk and to tailor recommendations involving the home setting, which can contribute to efforts aiming to help lower paediatric obesity rates.

\section{Conflict of interest statement}

No conflict of interest was declared. 


\section{Acknowledgements}

This study was supported by NIH grant 5R01HD06135.

\section{Author contributions}

$\mathrm{RHM}$ designed the study, analysed the data and drafted the initial manuscript. JCL, ALM and KR designed the data collection instruments, coordinated and supervised data collection, and critically reviewed the manuscript. NK, KEP and $A B$ provided input on the analysis plan and critically reviewed the manuscript. All authors have approved the final manuscript as submitted.

\section{References}

1. Ogden CL, Carroll MD, Kit BK, Flegal KM. Prevalence of childhood and adult obesity in the United States, 20112012. JAMA 2014; 311: 806-814.

2. U.S. Census Bureau. America's families and living arrangements. 2012. [WWW document]. URL http:// www.census.gov/prod/2013pubs/p20-570.pdf (accessed June 2014).

3. Hunsberger M, Formisano A, Reisch LA, et al. Overweight in singletons compared to children with siblings: the IDEFICS study. Nutr Diabetes 2012; 2: e35.

4. Ochiai H, Shirasawa T, Ohtsu T, et al. Number of siblings, birth order, and childhood overweight: a populationbased cross-sectional study in Japan. BMC Public Health 2012; 12: 766

5. Hesketh K, Crawford D, Salmon J, Jackson M, Campbell K. Associations between family circumstance and weight status of Australian children. Int J Pediatr Obes 2007; 2: 86-96.

6. Chen A, Escarce J. Family structure and childhood obesity, Early Childhood Longitudinal Study - Kindergarten Cohort. Prev Chronic Dis 2010; 7: A50.

7. Wells JC, Hallal PC, Reichert FF, Dumith SC, Menezes AM, Victora CG. Associations of birth order with early growth and adolescent height, body composition, and blood pressure: prospective birth cohort from Brazil. Am J Epidemiol 2011; 174: 1028-1035.

8. Koziel S, Kolodziej $\mathrm{H}$. Birth order and BMl in teenage girls. Coll Antropol 2001; 25: 555-560.

9. Jelenkovic A, Silventoinen K, Tynelius P, Myrskyla M, Rasmussen F. Association of birth order with cardiovascular disease risk factors in young adulthood: a study of one million Swedish men. PLOS ONE 2013; 8: e63361.

10. Stettler N, Tershakove A, Zemel B, et al. Early risk factors for increased adiposity: a cohort study of African American subjects followed from birth to young adulthood. Am J Clin Nutr 2000; 72: 378-383.

11. Lissau I, Sorensen T. Parental neglect during childhood and increased risk of obesity in young adulthood. Lancet 1994; 343: 324-327.

12. Hesketh K, Carlin J, Wake M, Crawford D. Predictors of body mass index change in Australian primary school children. Int J Pediatr Obes 2009; 4: 45-53.

13. Haugaard LK, Ajslev TA, Zimmermann E, Angquist L, Sorensen TI. Being an only or last-born child increases later risk of obesity. PLOS ONE 2013; 8: e56357. 14. Lovenheim M, Mumford K. Do family wealth shocks affect fertility choices? Rev Econ Stat 2013; 95: 464-475. 15. Raley S, Bianchi S. Sons, daughters, and family processes: does gender of children matter? Annu Rev Sociol 2006; 32: 401-421.

16. Epstein LH, Paluch RA, Raynor HA. Sex differences in obese children and siblings in family-based obesity treatment. Obes Res 2001; 9: 746-753.

17. Nord M, Andrews M, Carlson S. Household food security in the United States. 2004. [Economic Research Report no. 11]. [WWW document]. URL http://ssrn.com/ abstract=878333 (accessed June 2014).

18. Radloff L, Locke B. The community mental health assessment survey and the CES-D scale. Comm Surv Psych Dis 1986; 4: 177-188.

19. Oken E, Kleinman K, Rich-Edwards J, Gillman M. A nearly continuous measure of birth weight for gestational age using a United States national reference. BMC Pediatr 2003; 3: 6 .

20. U.S. Census Bureau. Births, deaths, marriages, and divorces. 2012 [National Vital Statistics Report for 2008]. WWW document]. URL http://www.census .gov/compendia/statab/cats/births_deaths_marriages _divorces.html (accessed June 2014).

21. Rindfuss RR, Bumpass LL. How old is too old? Age and the sociology of fertility. Fam Plann Perspect 1976; 8: 226-230.

22. Whitaker RC. Predicting preschooler obesity at birth: the role of maternal obesity in early pregnancy. Pediatrics 2004; 114: e29-e36.

23. Trent K, Spitze G. Growing up without siblings and adult sociability behaviors. J Fam Issues 2011; 32: 11781204.

24. Dodge J, Silva PA. A study of mothers' health. New Zeal Med J 1980; 91: 352-354.

25. Abrams B, Heggeseth B, Rehkopf D, Davis E. Parity and body mass index in US women: a prospective 25-year study. Obesity (Silver Spring) 2013; 21: 1514-1518.

26. Rose D, Bodor JN. Household food insecurity and overweight status in young school children: results from the Early Childhood Longitudinal Study. Pediatrics 2006; 117: 464-473.

27. Duarte CS, Shen S, Wu P, Must A. Maternal depression and child BMI: longitudinal findings from a US sample. Pediatr Obes 2012; 7: 124-133.

28. Hughes SO, Shewchuk RM, Baskin ML, Nicklas TA, Qu H. Indulgent feeding style and children's weight status in preschool. J Dev Behav Pediatr 2008; 29: 403.

29. Kaplan SG, Arnold EM, Irby MB, Boles KA, Skelton JA. Family systems theory and obesity treatment applications for clinicians. Infant Child Adolesc Nutr 2014; 6: 24-29.

30. Kramer L. Experimental interventions in sibling relationships. In: Rand D. Conger, Frederick O. Lorenz, K. A. S. Wickrama (eds) Continuity and Change in Family Relations: Theory, Methods, and Empirical Findings. Taylor \& Francis e-Library: Mahwah, New Jersey, USA, 2008. 